present edition will increase its usefulness as a book of reference. These show clearly how popular carbolic acid has become as a cause of death in suicide and from accident, and strongly supports the wellknown contention of the author, that some restriction should be placed upon the sale of this poison. At present carbolic acid stands at the head of the list of poisons causing death in cases of suicide, and is only exceeded in cases of accidental poisoning by lead, opium, and chloroform, in all of which there exists special reasons for the frequency of accidental death resulting from their use.

Harvey Litthejohn.

\title{
Guide to the Clinical Examination and Treatment of Sick Children.
}

By Johs Thomson, M.D., F.R.C.P.Ed. Edinburgh : William F. Clay. 1898.

IN his preface Dr. Thomson says that "the scope of this book is essentially supplementary," and, having carefully read it, we have come to the conclusion that the book forms a most valuable adjunct to the ordinary text-book of medicine, and also an excellent guide to the practitioner. The first chapter deals with the growth and development of the child, with certain anatomical peculiarities special to children, and with the subjects of speech, sleep, and the development of the sensory functions. It is a section which gives much information, important to the practitioner who wishes to successfully treat children's diseases. Chapter ii. deals with the teeth and dentition subjects, about which many fallacious and harmful ideas are often entertained, and we are glad to see that the author utters a warning against the common habit of ascribing so many infantile ailments to teething; but at the same time he does not fail to rightly describe a list of complaints as being associated with, but not caused by teething. From this list we are somewhat surprised to see that Dr. Thomson leaves out the enlargement of the glands at the angle of the jaw, so common in a baby cutting its teeth. Again, in his description of Hutchinson's teeth, he does not say that it is probable that their presence or absence depends on whether the child has or has not had syphilitic stomatitis. The description of the general clinical examination of the child is good, and the author lays stress on the fact that, in a child even more than in an adult, an accurate diagnosis depends on a complete physical examination of the patient. The next few sections deal with the examination of particular regions, the head and neck being considered first. We are glad to see that the author holds the opinion that craniotabes is, as a rule, merely a manifestation of rickets, but that undoubtedly the most severe cases occur in children who are rickety but also syphilitic. It would have been well, in enumerating the causes of enlarged cervical glands, to have expressly mentioned the frequency of the association of enlargement of the glands at the angle of the jaw with the presence of adenoid growths in the naso-pharynx. In the description of the examination of the abdomen, we note that no mention is made of the importance of, in many cases, feeling for a commencing psoas abscess, for swelling about the vermiform appendix, or for enlarged iliac glands.

One of the most valuable chapters in the book is that on the feeding 
of infants and children. The author treats the question in a concise and practical, and at the same time a scientific manner, and his remarks are worthy of being carefully read and thought over. We may safely say that Dr. Thomson has written a book which has great and obvious merits, and which should be widely read.

Leonard Gamgee.

Atlas of Methods of Clinical Investigation. By Dr. Chr. JAKOß. Authorised Translation from the German. Edited by AugusTuS A. Eshner, M.D. London: The Rebman Publishing Co. Ltd. 1898.

THIs is an English version of a book which in its original form has already met with a very favourable reception in this country. It is Volume xv. of Lehmann's well-known "Hand Atlases of Medicine," and with the same author's "Atlas of Diseases of the Nervous System," which, if we mistake not, has also appeared in an English form, completely covers the ground of clinical medicine. We know of no work to equal this in its special line, in the number, the accuracy, and the usefulness of its coloured illustrations. The various appearances of the blood, the sputum, and the urine, in health and disease, are very beautifully as well as faithfully reproduced.

The series of illustrations representing the physical signs of diseases of the chest and abdomen are of great practical value, and ought to be most helpful to the student. The book, however, is not simply an atlas. There are 259 pages of letterpress, in addition to the descriptions of the illustrations, and a thoroughly practical though necessarily brief account is given of clinical methods of investigation.

The translation is on the whole well done, but is somewhat unequal. Although the editor says an endeavour has been made to convey the spirit rather than the language of the original, we think the English version bears too strong evidence of its Teutonic origin. Some curious mistakes have crept in. The note to the description of Fig. 2, Plate i., is quite unintelligible- " The relation between the white and the red blood corpuscles will be correct if the field as portrayed be conceived to contain three times as many red blood corpuscles as white, the number of white remaining as in the illustration." The original puts it quite clearly - "The proportion will be correct if the field be supposed three times larger and filled in with red blood corpuscles, the number of white remaining the same." The description of Plate xxx. is quite wrong, as it stands, simply because the translator throughout has used "left" instead of "right." "The error has probably crept in through a mistranslation of "In ähnlicher Weise wie der Patient der Tafel xxix.," as "The patient whose case is illustrated in Plate xxix."

We were a little puzzled at finding "bran" mentioned as diet for diseases of the stomach, until, consulting the original, we found it was the translation of "Hirn." "Squab" is not a very well-known article of food in England, but it is the translation of "Taube," and so we suppose means "pigeon."

We may add that we miss the diphthong in this book, and its absence causes many words, such as "edema," " esophagus," "egophony," "feces," etc., to appear unfamiliar. Hector Mackenzie. 